\title{
Variation of magnetic properties in sedimentary rocks hosting the Foum Zguid dyke (southern Morocco): Combined effects of re-crystallization and Fe-metasomatism
}

\author{
Pedro F. Silva ${ }^{a, b, *}$, Bernard Henry ${ }^{c}$, Fernando O. Marques ${ }^{d}$, António Mateus ${ }^{\mathrm{e}}$, \\ Pedro Madureira ${ }^{\mathrm{f}}$, Nuno Lourenço ${ }^{\mathrm{b}, \mathrm{g}}$, Jorge Miguel Miranda ${ }^{\mathrm{b}}$ \\ a ISEL/DEC, R. Conselheiro Emídio Navarro, 1, 1950-062 Lisboa, Portugal \\ ${ }^{\mathrm{b}}$ CGUL, Universidade de Lisboa, Edificio C8, Piso 6, 1749-016, Lisboa, Portugal \\ ${ }^{c}$ Geomagnetism and Paleomagnetism, IPGP and CNRS, 4 Av. de Neptune, 94107 Saint-Maur cedex, France \\ d Dep. Geologia and CGUL, Fac. Ciências, Univ. Lisboa, Edificio C6, Piso 2, 1749-016, Lisboa, Portugal \\ e Dep. Geologia and CREMINER Fac. Ciências, Univ. Lisboa, Edificio C2, Piso 5, 1749-016, Lisboa, Portugal \\ ${ }^{\mathrm{f}}$ Centro de Geofisica de Évora and Dep. de Geociências da Univ. de Évora, R. Romão Ramalho, 59, 7000-671 Évora, Portugal \\ g Centro de Investigação Marinha e Ambiental da Universidade do Algarve, Portugal
}

Received 25 February 2005; received in revised form 7 September 2005; accepted 8 October 2005

Available online 13 December 2005

Editor: R.D. van der Hilst

\begin{abstract}
The effects of dyke intrusion on the magnetic properties of host sedimentary rocks are still poorly understood. Therefore, we have evaluated bulk magnetic parameters of standard palaeomagnetic samples collected along several sections across the sediments hosting the Foum Zguid dyke in southern Morocco. The study has been completed with the evaluation of the magnetic fabric after laboratory application of sequential heating experiments.

The present study shows that: (1) close to Foum Zguid dykes, the variations of the bulk magnetic parameters and of the magnetic fabric is strongly related with re-crystallization and Fe-metasomatism intensity. (2) The thermal experiments on AMS of samples collected farther from the dyke and, thus, less affected by heating during dyke emplacement, indicate that $300-400{ }^{\circ} \mathrm{C}$ is the minimum experimental temperature necessary to trigger appreciable transformations of the pre-existing magnetic fabrics. For temperatures higher than ca. $580{ }^{\circ} \mathrm{C}$, the magnetic fabric transformations are fully realized, with complete transposition of the initial fabric to a fabric similar to that of samples collected close to the dyke. Therefore, measured variations of the magnetic fabric can be used to evaluate re-crystallization temperatures experienced by the host sedimentary rock during dyke emplacement. The distinct magnetic behaviour observed along the cross-sections strongly suggests that samples collected farther from the dyke margins did not experience thermal episodes with temperatures higher than $300{ }^{\circ} \mathrm{C}$ after dyke emplacement. (3) AMS data shows a gradual variation of the magnetic fabric with distance from the dyke margin, from sub-horizontal $K_{3}$ away from the dyke to vertical $K_{3}$ close to the dyke. Experimental heating shows that heat alone can be responsible for this strong variation. Therefore, such orientation changes should not be unequivocally interpreted as the result of a stress field (resulting from the emplacement of the
\end{abstract}

\footnotetext{
* Corresponding author. ISEL/DEC, R. Conselheiro Emídio Navarro, 1, 1950-062 Lisboa, Portugal. Tel.: +351 217500882 ; fax: +351 21 7500977.

E-mail address: pmfsilva@fc.ul.pt (P.F. Silva).
} 
dyke, for instance). (4) Magnetic studies prove to be a very sensitive tool to assess rock magnetic transformations, thermally and chemically induced by dyke intrusion in hosting sediments.

(c) 2005 Elsevier B.V. All rights reserved.

Keywords: rock magnetism; contact metamorphism; natural AMS; thermal experiments; modified AMS; Fe-metasomatism

\section{Introduction}

The anisotropy of magnetic susceptibility (AMS) of a rock yields statistically preferred orientations of minerals. The interpretation in terms of fabric is not always straightforward, particularly in the case of very low susceptibility or of composite fabrics. The thermal treatment of samples often introduces mineralogical alterations that induce variations of the magnetic susceptibility [1]. Therefore, it has been used to modify the natural magnetic fabric, mostly expecting its simple enhancement (e.g., see [2-10]).

In rocks affected by contact metamorphism, such mineralogical alterations already occurred because of the thermal effect due to the intrusion. We have measured AMS during laboratory stepwise thermal treatment of samples taken at various distances from the intrusion. The aim has been to determine which samples had already undergone mineral alteration due to contact metamorphism and what was the maximum temperature reached at that time.

For this study, sedimentary rocks hosting dykes have been chosen which record contact metamorphism restricted to a thin aureole. The Foum Zguid dykes (southern Morocco) present suitable conditions for such a study. Sedimentary host rocks have been sampled (Fig. 1) along profiles perpendicular to the dykes at two outcrops with dykes with very different thickness. In addition to the AMS measurements during stepwise thermal treatment, detailed analyses of rock magnetism have been performed on the samples and study of the mineralogy and textural arrangements has been carried out by optical microscopy under transmitted and reflected light on polished thin sections of the most representative samples.

\section{Geological setting and sampling}

The great Foum Zguid dyke is related to the Pangaea break-up in Jurassic times $[11,12] .{ }^{40} \mathrm{Ar} /{ }^{39} \mathrm{Ar}$ radiometric age of $196.9 \pm 1.8 \mathrm{Ma}$ is reported by Sebai et al. [12] for this dyke. The two sampling sites (FZ8 and FZ11) involve sedimentary rocks belonging to the Adoudounian Series [13-15] close to the southern limit of the Bou-Azzer El Graara window in the Central Anti-Atlas Mountains. These series comprise continental clastic sediments and shallow oceanic carbonates [16] deposited in a basin developed

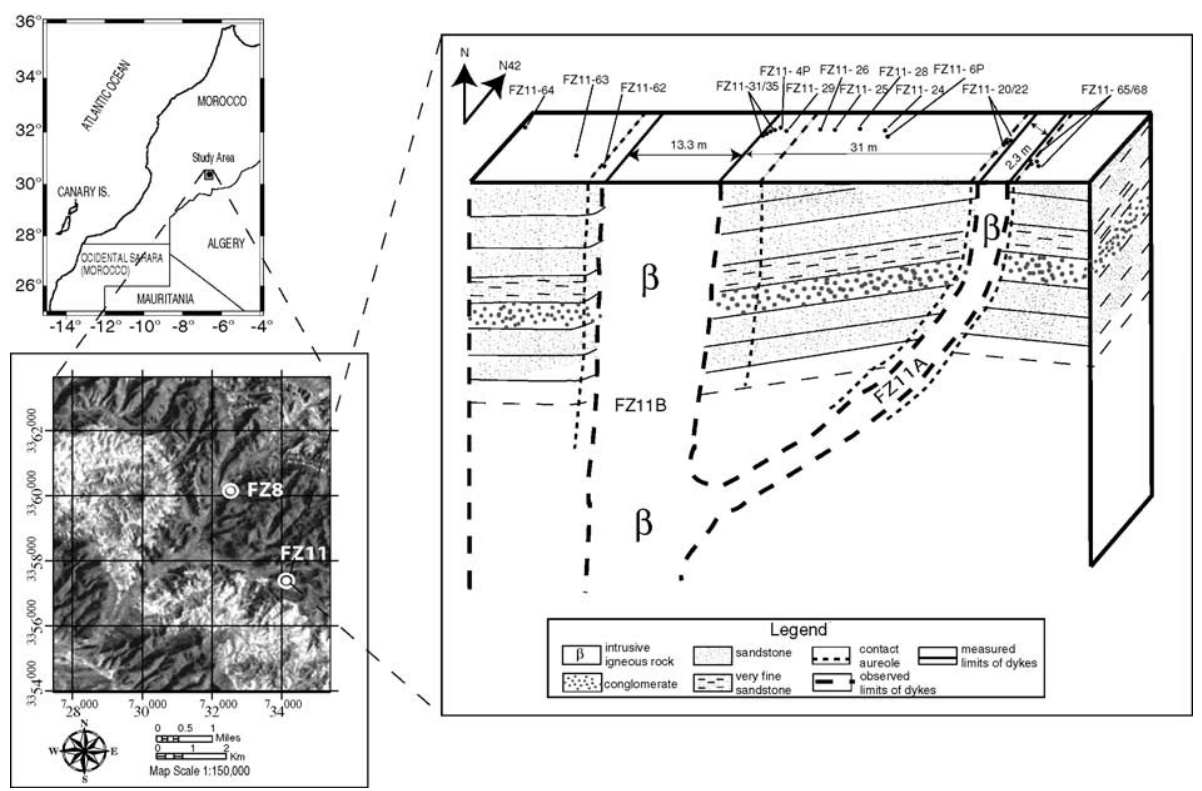

Fig. 1. Sketch map with location of the studied sites, FZ8 and FZ11, and geological sketch of FZ11. 
in Palaeo-Gondwana during the opening of the Theic Ocean [17].

At FZ8, the studied sedimentary rocks are located along the SE margin of the main Foum Zguid dyke. Here, the dyke trends $45^{\circ}$ in azimuth, it is vertical and approximately $100 \mathrm{~m}$ thick. The sampled sedimentary beds are dark grey and mainly comprise pelitic rocks and very fine-grained quartzites. In the first $6 \mathrm{~m}$ bordering the dyke, bedding $\left(S_{0}\right)$ cannot be recognized and fractures are rare, being limited to scarce sub-vertical discontinuities perpendicular to the dyke. Farther from the dyke, $S_{0}$ becomes clearly visible, slightly plunging $\left(6^{\circ}\right)$ to SE, and some fracture systems appear, the most penetrative comprising sub-vertical fractures running parallel to the dyke. 14 cores have been collected at
FZ8, covering a range of distances between 0.7 and $45 \mathrm{~m}$ from the dyke margin (Table 1).

FZ11 is characterized by the presence of two thinner dykes, FZ11A (to the SE) and FZ11B (to the NW), both vertical and running parallel to the main Foum Zguid dyke (local trend $42^{\circ}$ azimuth - Fig. 1). The distance between the two dykes at the sampling site is ca. $30 \mathrm{~m}$. However, $50 \mathrm{~m}$ topographically below, it can be seen that these two dykes represent two branches of the same intrusion. The average dyke thickness is ca. $2.5 \mathrm{~m}$ at FZ11A and ca. $13.5 \mathrm{~m}$ at FZ11B. The observed host rocks are mainly composed of fine-grained quartzwacke and greywacke with gently dipping bedding ( $S_{0}$ plunge is $8^{\circ}$ toward SE between the two dykes, $5^{\circ}$ toward NE southeast of FZ11A and $0^{\circ}$ northwest of

Table 1

Magnetic properties of the host rock samples

\begin{tabular}{|c|c|c|c|c|c|c|c|c|c|}
\hline Site & Sample & $\begin{array}{l}d \\
(\mathrm{~m})\end{array}$ & $\begin{array}{l}K \\
\left(10^{-3} \mathrm{SI}\right)\end{array}$ & $\begin{array}{l}\text { NRM } \\
(\mathrm{A} / \mathrm{m})\end{array}$ & $Q$ & $\mathrm{Tc}$ & $\mathrm{Hf}$ & $\mathrm{TFa}$ & Group \\
\hline \multirow[t]{14}{*}{ FZ8 (SE margin) } & FZ8-37 & 0.7 & 0.141 & 2.10 & 373.2 & $\swarrow$ & S & & A \\
\hline & FZ8-38 & 0.9 & 0.146 & 2.25 & 386.1 & $\swarrow$ & S & $\swarrow$ & A \\
\hline & FZ8-39 & 1.1 & 0.123 & 1.96 & 399.3 & $\swarrow$ & S & $\swarrow$ & A \\
\hline & FZ8-40 & 1.2 & 0.12 & 1.58 & 329.9 & $\swarrow$ & & & A \\
\hline & FZ8-41 & 2.4 & 0.147 & 1.94 & 330.68 & $\swarrow$ & S & & A \\
\hline & FZ8-42 & 3.3 & 0.165 & 2.01 & 334.5 & & $\mathrm{~S}$ & $\swarrow$ & A \\
\hline & FZ8-43 & 4.6 & 0.157 & 1.90 & 303.2 & $\swarrow$ & S & $\swarrow$ & A \\
\hline & FZ8-44 & 6.3 & 0.151 & 1.72 & 285.4 & & S & & A \\
\hline & FZ8-45 & 7.8 & 0.166 & 1.99 & 300.4 & $\swarrow$ & & $\swarrow$ & A \\
\hline & FZ8-46 & 9.6 & 0.173 & 2.36 & 341.8 & & S & $\swarrow$ & $\mathrm{A}$ \\
\hline & FZ8-47 & 12.6 & 0.173 & 2.38 & 344.7 & $\swarrow$ & S & $\swarrow$ & A \\
\hline & FZ8-48 & 17.3 & 0.189 & 2.04 & 270.5 & $\swarrow$ & S & $\swarrow$ & A \\
\hline & FZ8-49 & 29.0 & 0.197 & 1.11 & 141.2 & $\swarrow$ & S & $\swarrow$ & B \\
\hline & FZ8-50 & 45.0 & 0.232 & 0.28 & 30.2 & $\swarrow$ & $\mathrm{S}$ & $\swarrow$ & B \\
\hline \multirow[t]{4}{*}{ FZ11 (SE margin of A) } & FZ11-65 & 0.05 & 0.181 & 0.073 & 9.7 & $\swarrow$ & & & B \\
\hline & FZ11-66 & 0.3 & 0.161 & 0.016 & 2.5 & $\swarrow$ & & $\swarrow$ & $\mathrm{C}$ \\
\hline & FZ11-67 & 0.4 & 0.127 & 0.007 & 1.4 & & W & $\swarrow$ & $\mathrm{C}$ \\
\hline & FZ11-68 & 0.9 & 0.132 & 0.009 & 1.7 & $\swarrow$ & W & & $\mathrm{C}$ \\
\hline \multirow[t]{3}{*}{ FZ11 (NW margin of A) } & FZ11-20 & 0.6 & 0.55 & 0.06 & 5.0 & $\swarrow$ & S & & B \\
\hline & FZ11-21 & 0.5 & 0.47 & 0.10 & 10.9 & & S & $\swarrow$ & B \\
\hline & FZ11-22 & 0.40 & 0.4 & 0.06 & 7.2 & $\swarrow$ & $\mathrm{S}$ & & B \\
\hline \multirow[t]{9}{*}{ FZ11 (SE margin of B) } & FZ11-24 & 13.4 & 0.093 & 0.005 & 1.3 & $\swarrow$ & W & $\swarrow$ & $\mathrm{C}$ \\
\hline & FZ11-25 & 7.8 & 0.08 & 0.005 & 1.6 & 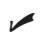 & & $\swarrow$ & $\mathrm{C}$ \\
\hline & FZ11-26 & 6.2 & 0.102 & 0.005 & 1.2 & $\swarrow$ & W & $\swarrow$ & $\mathrm{C}$ \\
\hline & FZ11-28 & 11.2 & 0.088 & 0.005 & 1.4 & $\swarrow$ & W & $\swarrow$ & $\mathrm{C}$ \\
\hline & FZ11-29 & 2.0 & 0.226 & 0.005 & 6.2 & $\swarrow$ & & & B \\
\hline & FZ11-31 & 1.2 & 0.251 & 0.43 & 42.9 & $\swarrow$ & S & $\swarrow$ & B \\
\hline & FZ11-32 & 0.4 & 0.274 & 0.53 & 48.5 & $\mathscr{L}$ & & $\mathscr{r}$ & A \\
\hline & FZ11-34 & 0.7 & 0.252 & 0.51 & 50.7 & $\swarrow$ & $\mathrm{S}$ & & A \\
\hline & FZ11-35 & 1.0 & 0.229 & 0.56 & 61.3 & $\swarrow$ & & $\swarrow$ & A \\
\hline \multirow[t]{4}{*}{ FZ11 (NW margin of B) } & FZ11-61 & 0.8 & 0.191 & 0.23 & 30.2 & $\mathscr{L}$ & S & $\swarrow$ & $\mathrm{B}$ \\
\hline & FZ11-62 & 1.4 & 0.259 & 0.29 & 28.1 & $\swarrow$ & S & $\swarrow$ & B \\
\hline & FZ11-63 & 4 & 0.143 & 0.008 & 1.5 & $\swarrow$ & & $\swarrow$ & $\mathrm{B}$ \\
\hline & FZ11-64 & 10.0 & 0.075 & 0.005 & 1.7 & $\swarrow$ & W & $\swarrow$ & $\mathrm{C}$ \\
\hline
\end{tabular}

$d$ - distance of sample from dyke margin; $K$ - magnetic susceptibility; NRM — natural remanent magnetization; $Q-$ Koenigsberger ratio; Tc thermomagnetic experiments performed; Hf — High field experiments performed; $S$ - samples characterized by simple hysteresis loops; $W$ samples characterized by wasp-waisted hysteresis loops; TFa — magnetic fabric obtained for different temperature steps; Group — see text; $\prec-$ indication of samples submitted to the different kinds of studies. 
FZ11B). The effects of re-crystallization and metasomatism are mesoscopically visible SE of the thicker FZ11B dyke. In fact, along the first $6 \mathrm{~m}$ away from the SE margin of this intrusion, the sedimentary rocks become black in colour; along the NW margin of the same dyke and around the thinner FZ11A dyke, no significant colour change has been observed. 20 cores have been collected in the host rocks along three crosssections at FZ11: from the SE margin of FZ11A, between the two dykes, and from the NW margin of FZ11B (Fig. 1 and Table 1).

\section{Petrography}

A detailed petrographic study has been performed on samples considered the most representative of both sites, at different distances from the intrusive dolerites.

Sedimentary rocks from FZ8 vary from quartz-rich pelites to fine-grained impure quartzites. In the samples nearest the margins (samples FZ8-37 and FZ8-41), variably corroded and sub-angular quartz micro-clasts (volcanic?) are embedded in a very fine-grained matrix quite enriched in quartz, muscovite ( \pm chlorite) and hematite, but also including sub-rounded grains of zircon and tourmaline besides plagioclase and amphibole (micro-clast?) relicts. Hematite (up to $22 \%$ of the modal composition of the matrix) occurs usually as fine-grained (microscopic to sub-microscopic) crystals that impregnate the silicate matrix uniformly or form aligned aggregates along trans-granular micro-fractures. This oxide is a product of intense Fe-metasomatism experienced by these rocks during the re-crystallization related to dyke emplacement. Locally, sub-rounded, isolated grains of millimetre dimension of hematite are also observed, perhaps resulting from inversion of a pre-existent spinel (maghemite or titanomaghemite?) during the heating related to the intrusion. The modal percentage of the matrix is lower in samples fart her located from the dyke margin (samples FZ8-47 and FZ8-49), with lower amount of disseminated hematite $(<8-10 \%$ of the modal composition).

Samples FZ11-35, FZ11-4P, FZ11-6P (collected between the two dykes at 1.0, 1.7 and $14 \mathrm{~m}$ from the SE margin of FZ11B, respectively) and FZ11-61 (collected at $0.8 \mathrm{~m}$ from the NW margin of FZ11B dyke) represent the host rocks at FZ11. According to their petrographic features, the samples farther located from the margins (samples FZ11-4P and FZ11-6P) can be classified as impure quartzite or quartzwacke, mainly composed of angular to sub-angular quartz and feldspar clasts (with average diameters up to $0.1 \mathrm{~mm}$ ) and lithoclasts (possibly volcanic in nature, displaying average diameters up to $0.8 \mathrm{~mm}$ ) set in a very fine-grained matrix of quartz and K-phyllosilicates fairly enriched in hematite. The relative proportion of the matrix varies considerably in each sample and is quite different for the two examined samples; also, the modal percentage of hematite and its distribution patterns are quite variable and very heterogeneous, but always record abundances below those reported for FZ8. Samples nearest the margins of the FZ11B dyke show a mineralogical composition and textural arrangement that justify their classification as quartzwacke or fine-grained greywacke, despite the effects due to incipient to moderate metasomatism. This is typically denoted by: a) development of products of feldspar hydrolysis; b) replacement of a preexistent, accessory clastic mineral (spinel?) by hematite; c) irregular dissemination of fine-grained hematite; and d) local growth of tiny pyrite crystals, often filling small inter-granular fractures.

According to the petrographic description above (paragenesis, texture and mineral transformations), it is clear that most fine hematite grains disseminated in the matrix were newly formed during Fe-metasomatism related with dyke emplacement, which is, therefore, an important feature of these sedimentary rocks adjoining the dolerite dykes. The intensity of hematite dissemination decreases with distance from the dyke margin, its growth indicating the prevalence of high oxidation conditions: $\log f \mathrm{O}_{2}$ values always above those determined by the hematite-magnetite buffer under $\mathrm{P}-\mathrm{T}$ conditions below $1 \mathrm{kbar}$ and ranging between ca. 400 ${ }^{\circ} \mathrm{C}$ and $300{ }^{\circ} \mathrm{C}$ (inferred from the stability fields of the prevailing phyllosilicates). This means an evolution of $\log f \mathrm{O}_{2}$ values from $\geq-27$ at $400{ }^{\circ} \mathrm{C}$ to $\geq-34$ at 300 ${ }^{\circ} \mathrm{C}$ in the presence of $\log f \mathrm{~S}_{2}$ values varying from $\leq-9$ at $400{ }^{\circ} \mathrm{C}$ to $\geq-10$ at $300{ }^{\circ} \mathrm{C}$ if pyrite is present.

\section{Rock magnetism}

The main magnetic phases have been examined by thermomagnetic analysis (susceptibility in low magnetic field with CS3 furnace apparatus coupled to KLY-3 susceptibilimeter - AGICO, Brno), up to a maximum temperature of $700{ }^{\circ} \mathrm{C}$ under Argon-controlled atmosphere. 11 and 18 samples from FZ8 and FZ11, respectively, have been selected for this study (see Table 1), representing different positioning and distances from dyke margins. A complex shape characterizes the thermomagnetic curves, mainly indicating the presence of several magnetic phases. For samples collected farther from the dyke margin at FZ11 (sample FZ11-24 in Fig. 2A), susceptibility increases during initial heating until about $550{ }^{\circ} \mathrm{C}$, then being followed by a significant 

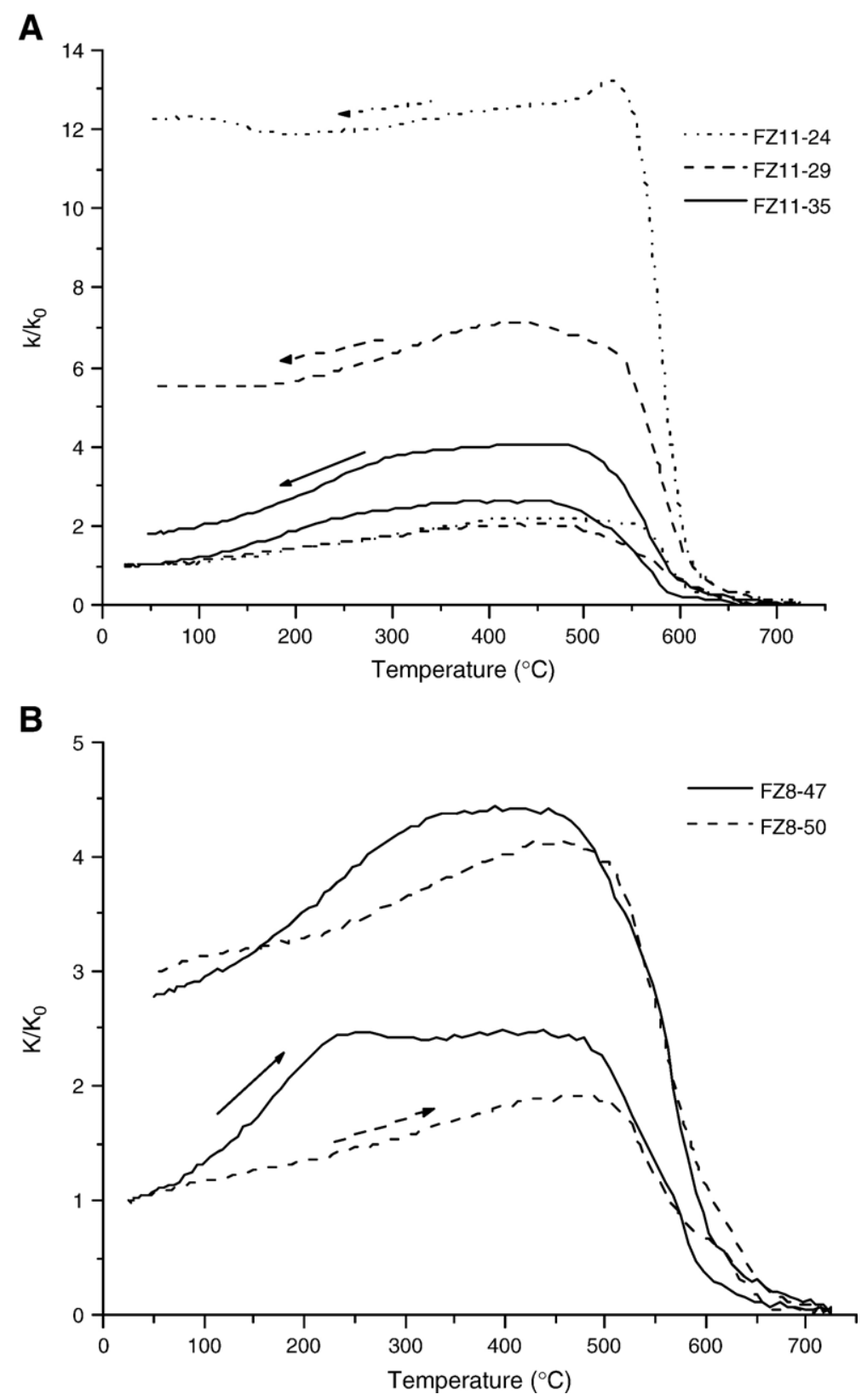

Fig. 2. Thermomagnetic curves, with most representative samples of FZ11 (A) and FZ8 (B).

decrease. For samples nearer the dykes margins (FZ847 or FZ11-35 in Fig. 2), the curve is similar for high temperatures, but records an increase in susceptibility only up to about $200-300{ }^{\circ} \mathrm{C}$ and develops a "plateau" of values until $500{ }^{\circ} \mathrm{C}$. Samples representative of intermediate distances relative to the dyke margins, also display transitional thermomagnetic behaviour (FZ1129 and FZ8-50 in Fig. 2).

Partial cooling experiments show that the curves are reversible at least until temperatures around $550{ }^{\circ} \mathrm{C}$, but not after heating at $700{ }^{\circ} \mathrm{C}$. During the final cooling stage, susceptibility is much higher but the general shape of the curve is similar to those obtained for heating curves. However, the susceptibility "plateau" achieved for samples nearest the dyke margins is strongly reduced. Therefore, the magnetic phase responsible for the "plateau" does not remain under high temperature conditions. The heating curve does not reveal any decrease around the pyrrhotite Curie temperature, which means that this sulphide is not 
present (and then not at the origin of this "plateau"), though pyrite has been observed in some samples collected at site FZ11. The mineral phase that disappears could be titanomaghemite inverting to ilmenohematite (possibly with some exsolution) or, less probably, titanomagnetite exsolving to magnetite and ilmenite [18]. For temperatures higher than 500-550 ${ }^{\circ} \mathrm{C}$, the decrease of susceptibility values allows the identification of two different magnetic phases until $650{ }^{\circ} \mathrm{C}$. One of them corresponds to hematite, responsible for the susceptibility decrease until temperatures around $650{ }^{\circ} \mathrm{C}$ [19]. For the other component, although the Curie temperature cannot be determined precisely because of the curves interference for both phases (Fig. 2B), a Curie temperature around $580{ }^{\circ} \mathrm{C}$ can be inferred, which could indicate the presence of titano-hematite or of a weak amount of magnetite. The observed higher susceptibility values during cooling suggest the occurrence of new hematite and magnetite, resulting from transformation at the highest temperature.

High field experiments have been performed on samples of about $1 \mathrm{~cm}^{3}$ by using a laboratory-made translation inductometer within an electromagnet. These experiments have been conducted until a maximum applied field of $800 \mathrm{mT}$ was reached for a total of 12 and 13 samples from FZ8 and FZ11, respectively. These samples display two distinct behaviours. All samples from FZ8 and 7 samples adjoining the dyke margins at FZ11 show apparently simple loops, without reaching saturation at $800 \mathrm{mT}$ (see sample FZ8-39 in Fig. 3). This high coercivity is in agreement with the dominating presence of hematite, as also shown by microscopy and thermomagnetic data. The remaining 6 samples from FZ11 (see Table 1) display wasp-waisted shapes (see sample FZ11-24 in Fig. 3). This indicates the presence of two main magnetic phases, one with high coercivity (most probably hematite) and the other with lower coercivity, as can be deduced from the steep increase in the beginning of the cycle. Such component with low coercivity should be a weak amount of magnetite rather than titano-hematite, which has generally higher coercivity [19]. All these samples belong to the SE margin of the thinner dyke (FZ11A) or have been collected farther from the borders of the thickest dyke (FZ11B).

\section{Magnetic properties according to distance from dyke margin}

\subsection{Bulk magnetic parameters}

FZ8 sedimentary host rocks show low bulk magnetic susceptibility $(K)$ values, ranging between 0.123 and $0.232 \times 10^{-3}$ SI (Table 1), but reveal a gradual and consistent increase with distance from the dyke margin (Fig. 4). On the contrary, the highest values of the natural remanent magnetization (NRM) (between 1.75 and $2.5 \mathrm{~A} / \mathrm{m}$ ) are observed for samples located in the 20 $\mathrm{m}$ nearest the dyke margin. A sharp decrease of NRM is

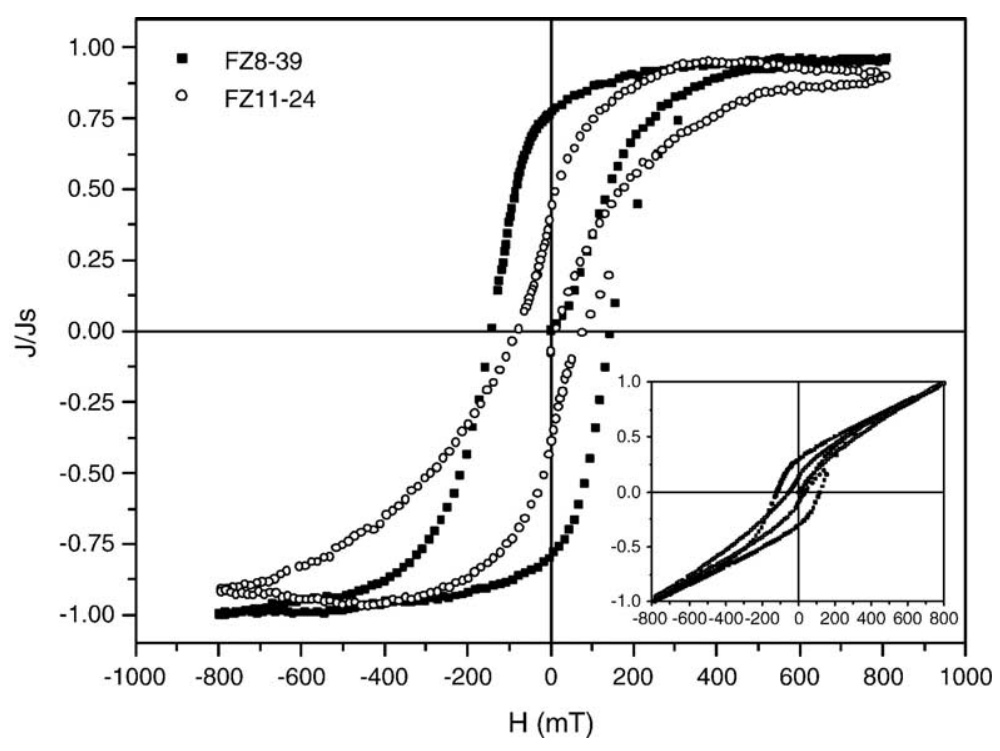

Fig. 3. Examples of hysteresis loops obtained for the sedimentary host rocks of FZ8 and FZ11. Hysteresis loops of samples FZ11-24 and FZ8-39 have been corrected for the high field slope and normalized by the maximum value. Inset shows original hysteresis loops only normalized by the maximum value. 


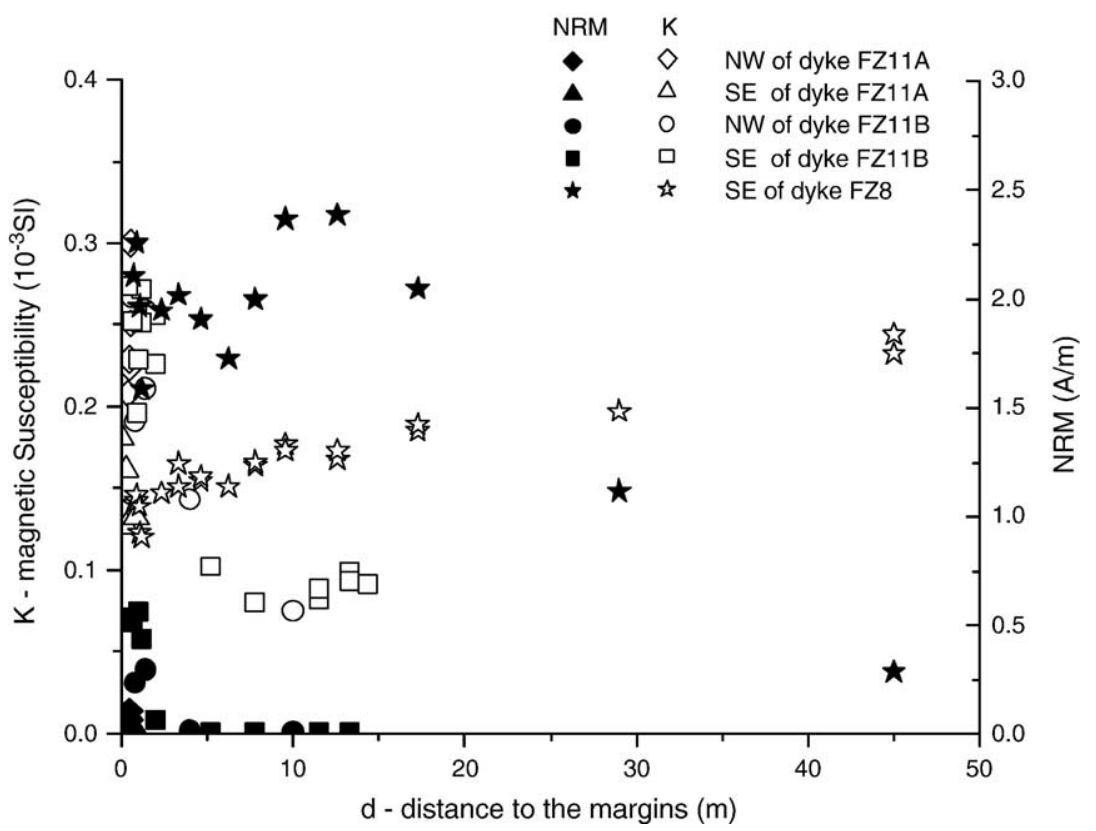

Fig. 4. Graph showing relationship between bulk magnetic susceptibility $K$ and natural remanent magnetization (NRM) according to distance from dykes margins at FZ8 and FZ11.

observed for greater distances, with values as low as $0.28 \mathrm{~A} / \mathrm{m}$ on samples located further than $45 \mathrm{~m}$. This contrasting behaviour of the remanent and induced magnetizations with distance results in a strong linear decrease of the Koenigsberger ratio, $Q$ (Fig. 5), from values as high as 399 for samples bordering the dyke to 30 for samples farther away.
Concerning FZ11, the NRM values are clearly higher for samples located on the first meter of both margins of the thickest FZ11B dyke (Fig. 4 and Table 1). The NRM values clearly decrease wit $h$ distance of sample from dyke, stabilizing with low values for distances greater than $4 \mathrm{~m}$. Regarding the thinner FZ11A dyke, samples at the NW margin (i.e. the side facing

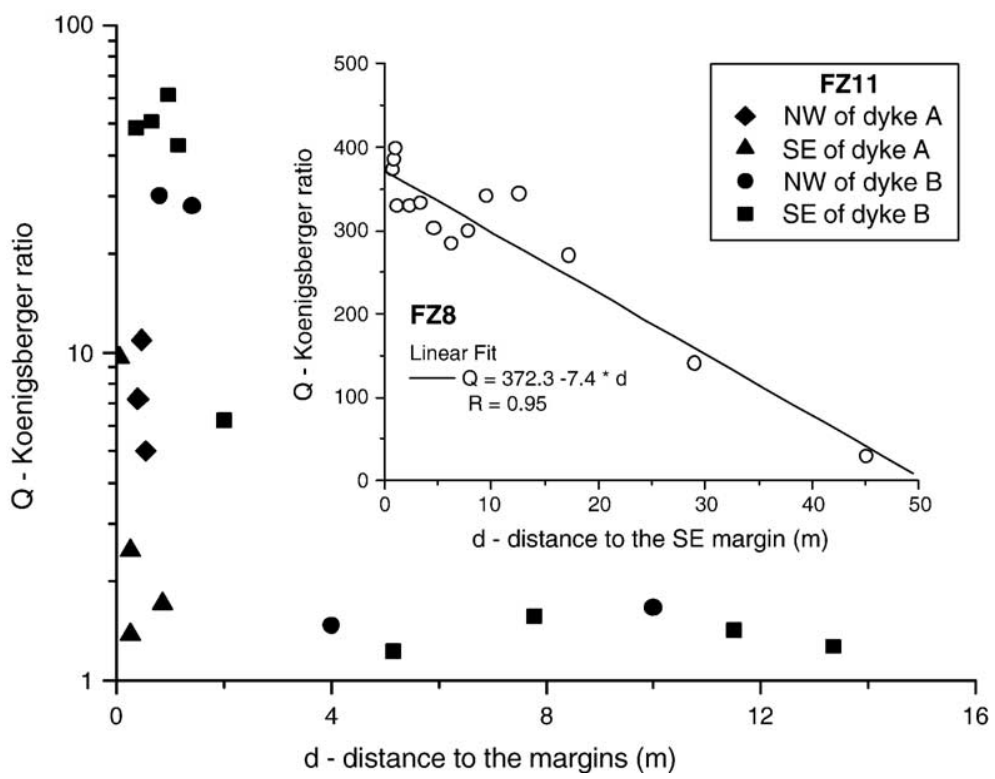

Fig. 5. Koenigsberger ratio $Q$ as a function of the distance from dyke margin for FZ11. Inset corresponds to FZ8, with indication of the best linear fit. 
FZ11B) reveal higher values than those in the SE margin, but the magnitude of NRM is always below the values obtained for the margins of FZ11B. The behaviour of $K$ with distance of sample from dyke follows the general trend shown by NRM, but with lower difference between maximum and minimum values. Therefore, the Koenigsberger ratio is also here higher for samples located nearest the dyke margins. Samples located further than $4 \mathrm{~m}$ from the dyke show lower and constant $Q$.

\subsection{Magnetic fabric}

The anisotropy of magnetic susceptibility (AMS) measures the preferred orientation of individual minerals (crystalline and shape anisotropy) in rocks [20,21]. The AMS ellipsoid is defined by a second-rank tensor, the principal axes being defined as $K_{1} \geq K_{2} \geq K_{3}$. The corrected degree of anisotropy $P^{\prime}$ and shape parameter $T$ have been used [22] to characterize the AMS ellipsoid. The interpretation of the magnetic fabric at site scale

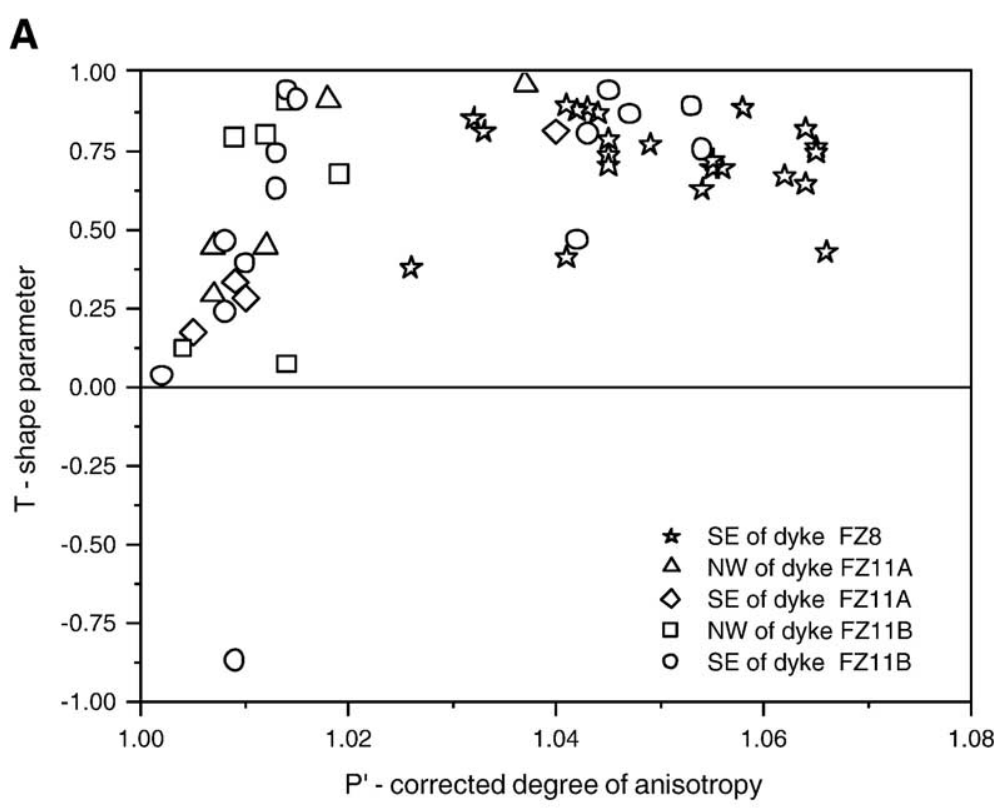

B

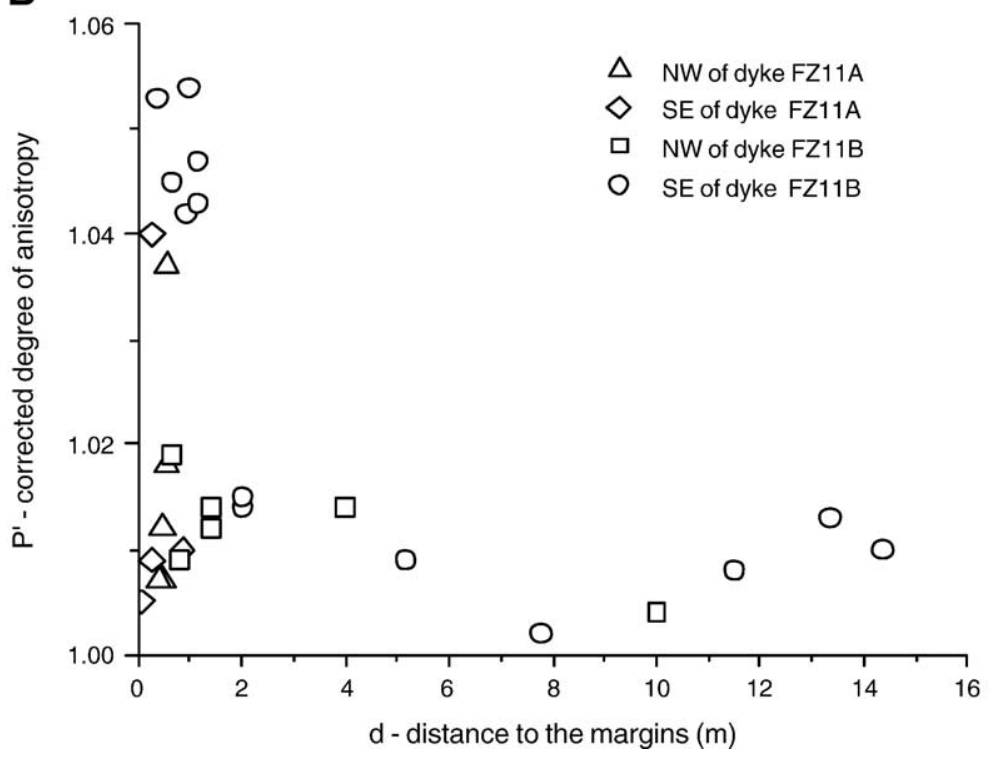

Fig. 6. (A) Jelinek [22] plot: shape parameter $T$ vs. corrected degree of anisotropy $P^{\prime}$ for samples of the two sites. (B) Corrected degree of anisotropy $P^{\prime}$ vs. the distance from the dykes margins $d$. 


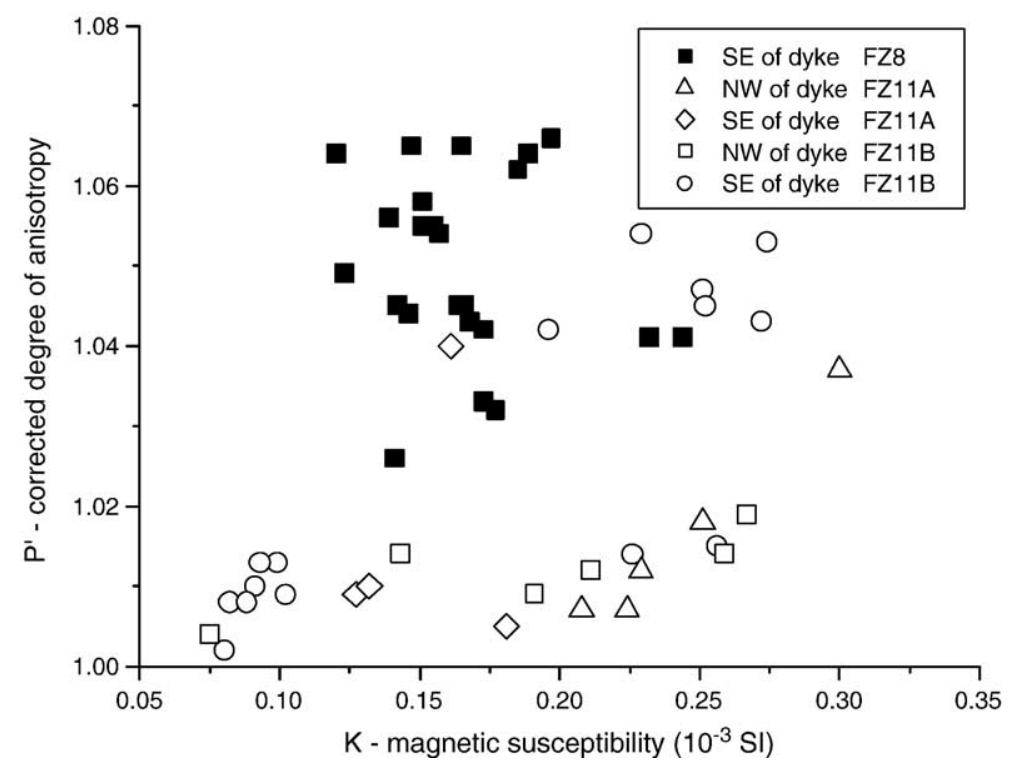

Fig. 7. Corrected degree of anisotropy $P^{\prime}$ vs. magnetic susceptibility $K$ for FZ8 and FZ11 samples.
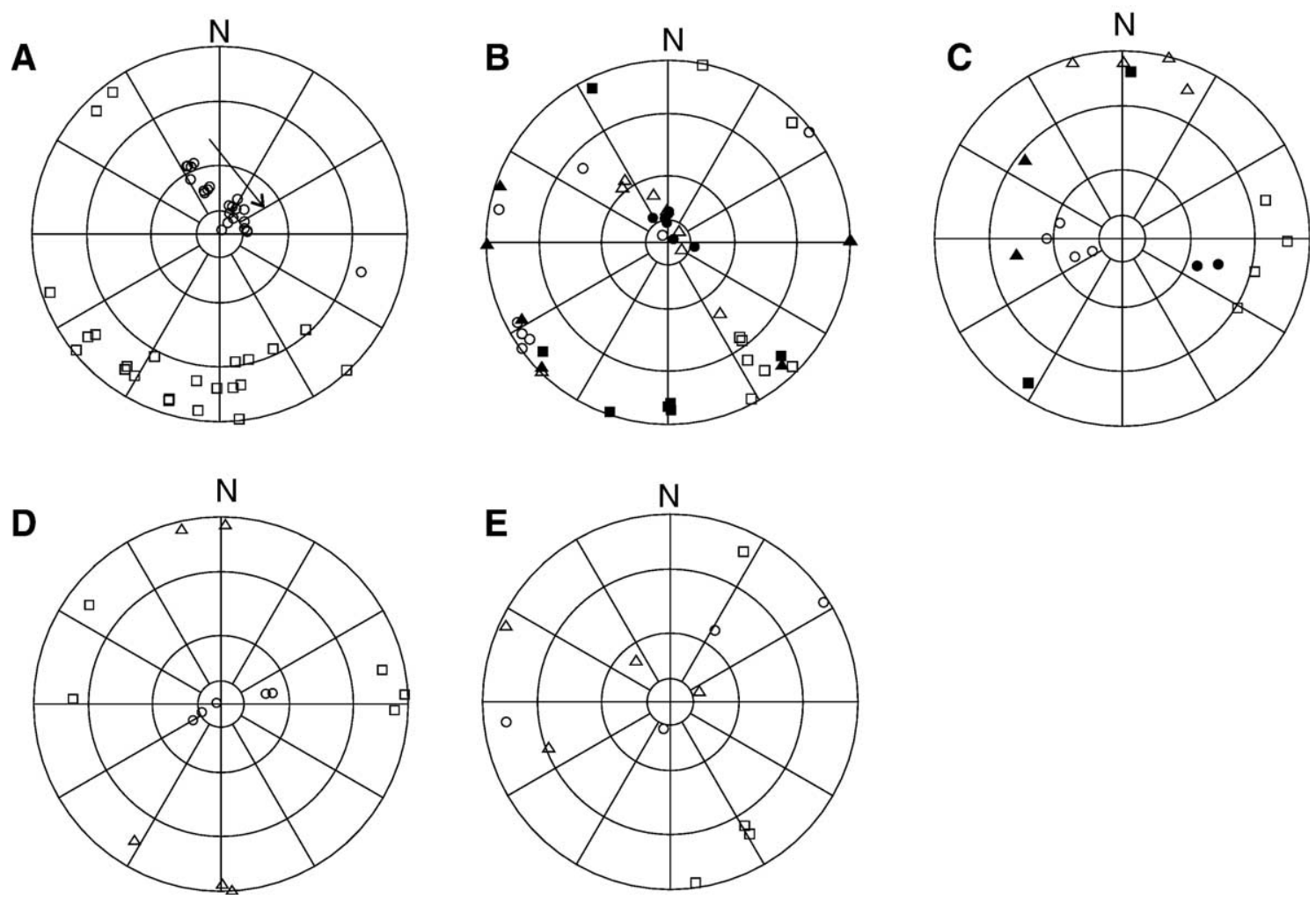

Fig. 8. Stereographic projections with squares, triangles and circles corresponding to the maximum $K_{1}$, intermediate $K_{2}$ and minimum $K_{3}$ principal axes of the magnetic susceptibility ellipsoid, respectively. (A) FZ8 samples, with arrow indicating the sense of distance increase from dyke margin. (B) Samples located at FZ11B SE margin; filled symbols for samples located at a distance less than 2 m from dyke margin and open symbols for samples located at distances greater than $2 \mathrm{~m}$. (C) Samples located at FZ11B NW margin; filled symbols correspond to samples located at 4 and 14 $\mathrm{m}$, while open symbols correspond to the samples located at the nearest $1.4 \mathrm{~m}$. (D) Samples located at FZ11A NW margin. (E) Samples located at FZ11A SE margin. 
has been made using the statistics for second-rank tensors [23]. The studied samples show, mostly, oblate $(T>0)$ susceptibility ellipsoids (Fig. 6), the highest flattening being characteristic of samples adjacent to dykes margins. $P^{\prime}$ for FZ8 samples has high and consistent values. In contrast, FZ11 samples reveal significant variations of $P^{\prime}$ with distance from dyke margins (Fig. 6B). At the SE margin of the thicker FZ11B dyke, $P^{\prime}$ values decrease with distance from dyke margin. On each margin of the thinner FZ11A dyke, one sample shows higher $P^{\prime}$ values, but no consistent behaviour could be observed. To determine if $P^{\prime}$ values are sensitive to the amount or nature of the magnetic carriers, this parameter has bee $\mathrm{n}$ plotted as a function of $K$ (Fig. 7): samples belonging to the NW margin of FZ11A and to both FZ11B margins show systematically higher $P^{\prime}$ values for higher $K$ values. In contrast, samples from FZ8 do not show any obvious correlation of $P^{\prime}$ with $K$.

Concerning susceptibility ellipsoid orientation, FZ8 samples show a progressive evolution towards steeper plunges of $K_{3}$ in the $136^{\circ}$ azimuth, which appears to be related to an increase in distance from the dyke margin (Fig. 8A). The magnetic foliation in samples located further than $5 \mathrm{~m}$ from the dyke margin shows a gentle SW dip, coincident with $S_{0}$. Close to the dyke margins, the bedding plane cannot be recognized, and it is not possible to determine if the plunge variation of the magnetic foliation is related to a dip variation of $S_{0}$ or to any other feature related with the composite nature of the fabrics.

FZ11 samples show different magnetic fabrics for both dykes and as a function of distance from dykes margins. For the SE margin of FZ11B, samples located in the first $2 \mathrm{~m}$ (Fig. 8B) present sub-horizontal magnetic foliation (sub-parallel to $S_{0}$ ) with well grouped $K_{3}$, and $K_{1}$ and $K_{2}$ scattered around a low-plunging plane (here called fabric II). Farther from the dyke margins, the magnetic fabric is completely different (Fig. 8B), mainly with a sub-vertical magnetic foliation and three major clusters of the susceptibility axes (fabric I). Each of these clusters includes axes of 2 or 3 different types $\left(K_{1}, K_{2}\right.$ and $\left.K_{3}\right)$. For the 6 samples collected at the NW margin of FZ11B, again different magnetic fabrics are observed as a function of distance from dyke margin (Fig. 8C). $K_{3}$ for samples located within the nearest $1.4 \mathrm{~m}$ shows steep westward plunge, while for samples further from the dyke, $K_{3}$ plunges eastward. $K_{1}$ for samples located at the nearest $1.4 \mathrm{~m}$ shows gentle dip to the $\mathrm{E}$ direction, while for samples further from the dyke, $K_{1}$ is sub-horizontal in a N-S direction. Samples located at the NW margin of FZ11A have $K_{3}$ grouped wit h steep plunge, and $K_{1}$ preferably aligned along the $90^{\circ}$ azimuth (Fig. 8D). At the SE margin of FZ11A, $K_{3}$ is randomly distributed around a vertical ENE-WSW plane, and $K_{1}$ is preferably oriented along the $160^{\circ}$ azimuth with gentle plunge (Fig. 8E).

\section{Characterization of the magnetic properties by laboratory heating experiments}

In this section, the evolution of bulk magnetic parameters and magnetic fabric measured at room temperature has been analysed after different sequential heating treatments with increasing maximum temperature (up to $670{ }^{\circ} \mathrm{C}$ ), each during $1 \mathrm{~h}$. The aim has been a better understanding of the heating effects on host sediments by dyke emplacement and, in particular, the temperature experienced by the host rocks during recrystallization. For this purpose, 10 and 14 samples from FZ8 and FZ11, respectively, have been selected according to the measured magnetic properties and distance from the dykes margins (see Table 1).

\subsection{Bulk magnetic parameters}

The evolution of $K$ at room temperature during thermal treatments, despite a few exceptions, is very similar for both sampled sites (Fig. 9A and B). A gradual decrease of $K$ is mainly observed after heating at temperatures ranging between 300 and $580{ }^{\circ} \mathrm{C}$. Between 580 and $670{ }^{\circ} \mathrm{C}, K$ shows a small variation. At FZ8, samples located further from the contact display a considerable and gradual decrease of $K$ for temperatures higher than $300{ }^{\circ} \mathrm{C}$.

\subsection{Magnetic fabric}

During heating experiments, the $T$ parameter has shown strong stability for a large number of samples from FZ8, recording just a smooth increase in samples located farther from the dyke margin (Fig. 9C). Samples from FZ11 show two distinct behaviours regarding $T$ (Fig. 9D): i) samples closer to the dykes have stable T, similar to that observed for FZ8 samples; ii) samples further from the dyke display complex transitions between oblate and prolate shapes - they change from oblate to prolate shape between room temperature and $350-400{ }^{\circ} \mathrm{C}$, and from prolate to oblate at higher temperatures.

The $P^{\prime}$ values from FZ8 generally show a smooth decrease for temperatures ranging between 300 and 550 ${ }^{\circ} \mathrm{C}$ (Fig. 9E). For higher temperatures, a very weak variation of $P^{\prime}$ values is observed, except for the two samples farthest from the dyke margin (FZ8-49 and 

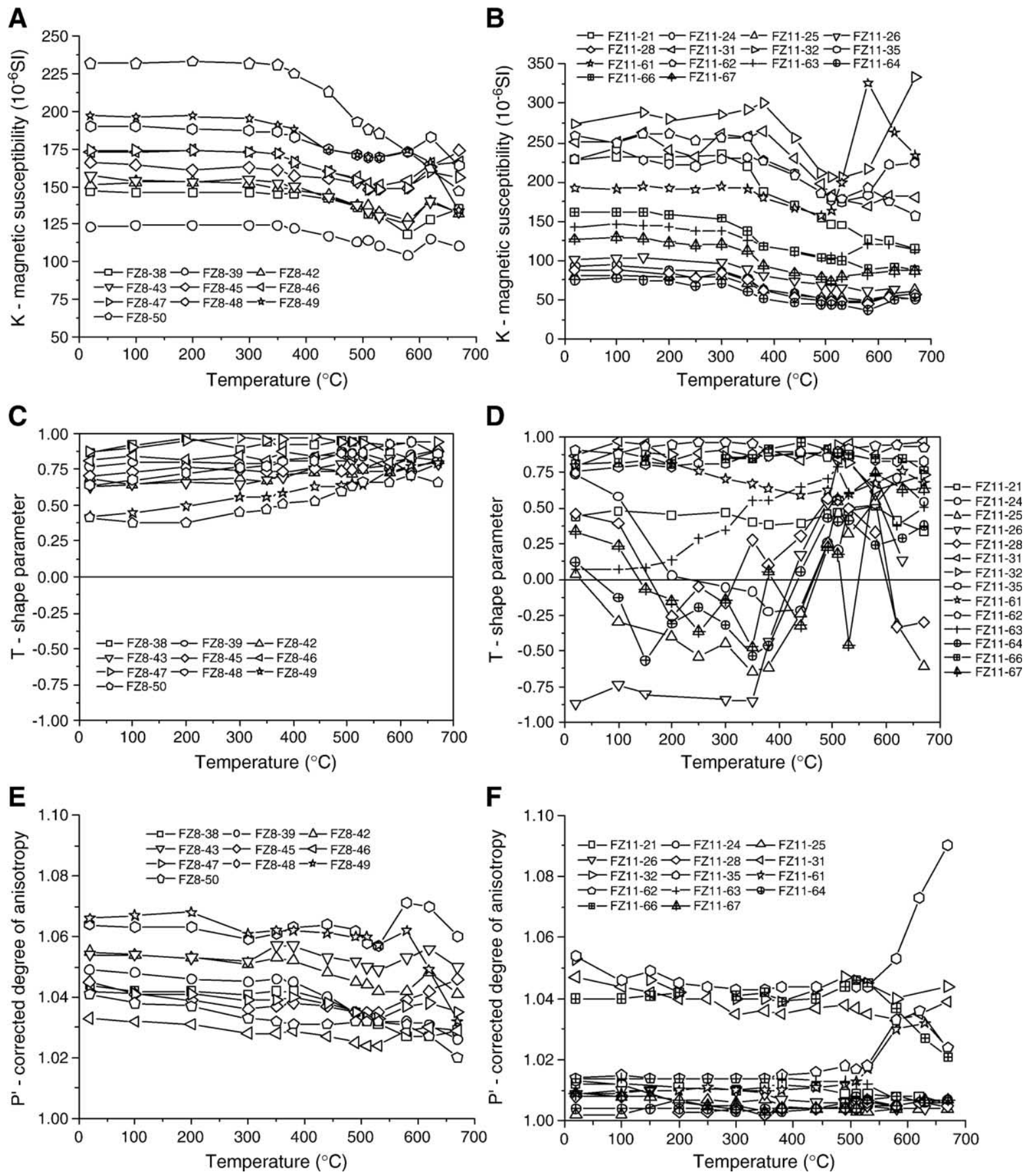

Fig. 9. Evolution of magnetic susceptibility $K$ and magnetic fabric ( $T$ and $P$ ) during heating for FZ8 (A, C and E) and FZ11 (B, D and F).

FZ8-50), which show a progressive decrease of $P$ ' For almost all the examined samples from FZ11, $P^{\prime}$ values do not vary significantly (Fig. 9F). However, samples adjoining the SE margin of FZ11B, have clearly acquired higher $P^{\prime}$ values, of the same order of magnitude of those obtained for samples from FZ8.
Concerning the principal magnetic susceptibility ellipsoid axes, samples from FZ8 show a stable orientation along all thermal treatments (Fig. 10A). In contrast, samples from FZ11 present an evolution of the principal axes as a function of distance. Samples adjoining the dykes margins (Fig. 10B) show stable axes orientation 


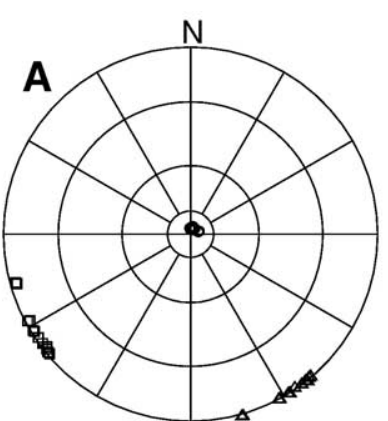

D

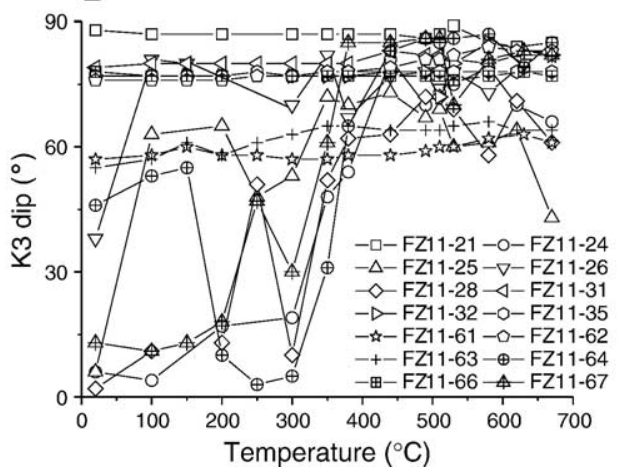

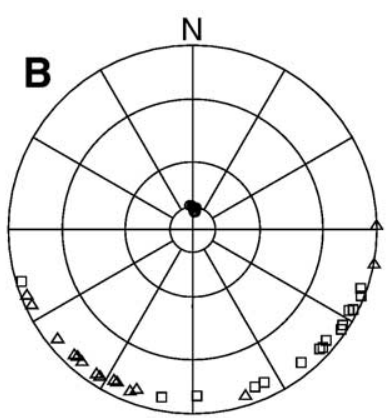

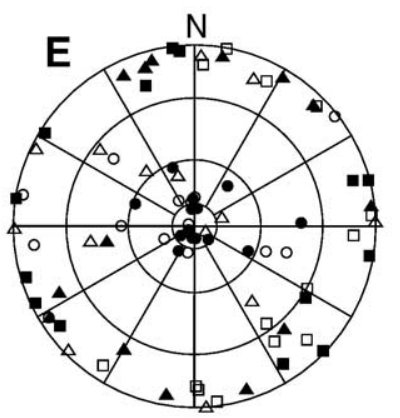

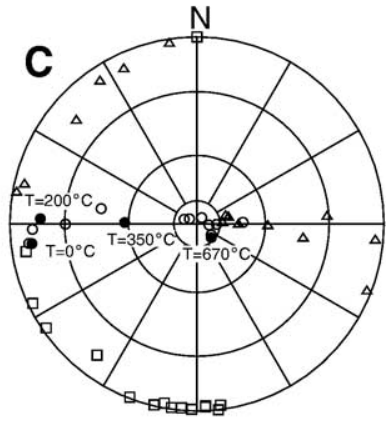

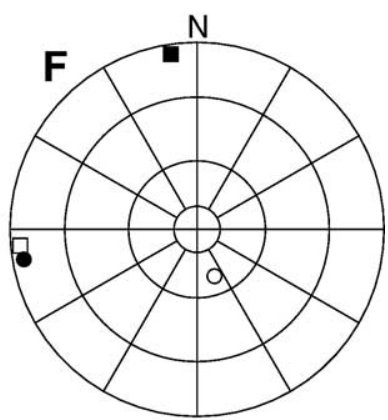

Fig. 10. (A and B) Stereographic projections of principal axes for different heating steps of samples FZ8-50 and FZ11-31, respectively. (C) Evolution of the magnetic fabric for several heating steps of sample FZ11-67, with indication of four thermal steps of the minimum axis evolution (filled circles). (D) $K_{3}$ plunge evolution with temperature for all FZ11 samples. (E) Magnetic fabric displayed by FZ11 samples before the heating steps (open symbols) and for the last heating step at $670{ }^{\circ} \mathrm{C}$ (filled symbols). (F) Example of the difference tensor results for sample FZ11-67, with open (filled) symbols representing the fabric II (fabric I). Maximum (squares), intermediate (triangles) and minimum (circles) symbols represent principal magnetic susceptibility ellipsoid axes.

for $K_{3}$, while $K_{1}$ and $K_{2}$ mainly record small variations along a great circle (fabric II). All remaining samples have undergone a progressive evolution of the principal axes during the sequential heating treatments. Before thermal treatment, they had, mostly, $K_{3}$ far from the vertical (fabric I). For temperature steps between 100 and $300{ }^{\circ} \mathrm{C}, K_{3}$ has systematically evolved towards an inclination between $60^{\circ}$ and $90^{\circ}$ (Fig. 10C and D). After maximum heating, the resulting magnetic fabric from all analysed samples reveals a remarkable difference from the initial pattern, with $K_{3}$ well grouped with inclination higher than $60^{\circ}$, and $K_{1}$ and $K_{2}$ distributed around a subhorizontal plane (Fig. 10E). After heating, the magnetic fabric of these samples has become, therefore, similar to that (fabric II) of samples near the dyke border, i.e. the most heated samples during dyke intrusion.

\subsection{Difference tensor}

To evaluate partial magnetic fabrics that could develop during each heating treatment, we have used the diagonalization of the tensor that results from the difference term to term of susceptibility tensors measured after and before this treatment [9]. For all FZ8 samples and for samples nearest the dykes at FZ11, the difference tensors reveal a magnetic fabric similar to that obtained before heating (Fig. 10A and B).

At FZ11, for samples farther from the dykes, the difference tensors reveal the disappearance of the magnetic fabric, with $K_{3}$ sub-horizontal (fabric I) during the entire thermal experiment up to $500-580{ }^{\circ} \mathrm{C}$. This vanishing is accompanied by a weak decrease of susceptibility. For higher temperatures, the difference tensor shows, conversely, a magnetic fabric appearing with $K_{3}$ sub-vertical (fabric II). An example of magnetic fabric after different thermal steps is reported in Fig. $10 \mathrm{C}$ and E. From difference tensors (Fig. 10F), the fabric that disappeared (fabric I) remains until temperatures of about $500{ }^{\circ} \mathrm{C}$; the new fabric (fabric II) emerges only at higher temperature (Fig. 10E), but the measured fabric (Fig. 10C) already shows a transition from fabric I to fabric II at lower temperature $\left(350{ }^{\circ} \mathrm{C}\right)$. Therefore, fabric II already existed in the sample before heating, and the initial fabric was composite. This is also corroborated by the observed changes of the fabric shape: oblate when vertical magnetic foliation (fabric I) dom- 
inates, prolate during the transition, and again oblate when the horizontal magnetic foliation (fabric II) transposes the earlier fabric (Fig. 9D).

Fabric II corresponds to the sedimentary fabric, with maximum axis possibly disturbed during dyke emplacement. The origin of fabric I is debatable. The existence of clusters of different kinds of axes suggests that it could be the inverse of fabric II (due to SD grains of magnetite or titanomaghemite), but in this case the maximum axis should have been mainly vertical in fabric I [24].

\section{Discussion}

The present magnetic and petrographic studies highlight the differential effects of contact metamorphism on host sedimentary rocks as a function of distance from the margins of dykes with different thickness, leading to the division of the studied samples into three groups.

- Group A comprises samples located nearest the margin of the thick dyke at FZ8 outcrop and the SE margin of the thicker dyke (FZ11B) at FZ11 outcrop (see Table 1 for sample identification); therefore the most affected by re-crystallization and Fe-metasomatism. Among all the collected samples, this group shows the highest content of hematite, reflecting the higher metasomatism. Thermomagnetic experiments allow us to infer the presence of three main magnetic carriers: 1) hematite; 2) probably titanomaghemite; and 3) possibly a weak amount of magnetite. The presence of hematite has been confirmed by the high field experiments and its importance for magnetization is largely dominant since no wasp-waisted hysteresis loops have been found for this group of samples. Titanomaghemite only occurs in this group of samples, but it has not been recognized during petrographic examination. However, we cannot rule out the possibility of titanomaghemite to represent a product of oxidation over a pre-existent spinel. Hematite mainly corresponds to the highest values of NRM and $Q$. Samples from FZ8 show an evolution of these parameters with distance from the dyke, recording a clear decrease of NRM and $Q$ with distance from the dyke. This evolution is compatible with the hematite content petrographically observed and resulting from the thermal effect experienced by the samples. Concerning the magnetic fabric, all samples show a similar shape and position of the three principal axes of the magnetic susceptibility ellipsoid. The study of the magnetic fabric during heating experiments reveals similar characteristics, suggesting the presence of the same fabric thermally stable until the maximum temperature used $\left(670{ }^{\circ} \mathrm{C}\right)$.

- Samples belonging to Group B also correspond to thermally modified sedimentary rocks, but located at greater distances from the dyke margins than samples of Group A (see Table 1). This group only revealed the presence of the two main magnetic phases with high Curie temperatures, i.e. hematite and possibly a weak amount of magnetite. While the magnetic fabric displays similar results for both groups $\mathrm{A}$ and $\mathrm{B}$, the NRM and $Q$ values are significantly lower than those for samples of Group A.

- Group C corresponds to samples located farthest from the dyke margins at FZ11. These samples do not show magnetic or petrographic evidence of significant re-crystallization or even Fe-metasomatism. The thermomagnetic behaviour is relatively similar to that of group $\mathrm{B}$, with clear $K$ decrease only observed for temperatures around $560{ }^{\circ} \mathrm{C}$. This implies the presence of only two magnetic phases, hematite and probably a weak amount of magnetite. The wasp-waisted shape of the hysteresis loops corroborates the presence of these two magnetic phases, the low coercivity phase (magnetite) having here a significant effect. Samples from Groups A and B do not show wasp-waisted loops, contrary to samples of Group C. This suggests that hysteresis loops are dominated by hematite for Groups A and B, and that the occurrence of wasp-waisted loops likely depends only on the relative proportion between magnetite and hematite. Because of the difference of magnetic susceptibility between magnetite and hematite, it is clear that the amount of magnetite is very small when compared to that of hematite. However, it appears to be sufficient to generate waspwaisted loops, only for group C samples. Such kind of loop is only visible in samples from FZ11, and particularly in the sediments less affected by the intrusion, i.e. around the thinner dyke and farther from the thickest. NRM, $K$ and $Q$ values are low and constant, showing no evolution with distance from the dyke margin. Concerning the magnetic fabric, very distinct orientations from that observed in the other groups have been obtained. However, when submitted to sequential heating experiments, the magnetic fabric for group $\mathrm{C}$ evolves towards the same fabric as in the other groups. This is interpreted as a consequence of the competition between two fabrics, fabric I and fabric II. Previous to the contact metamorphism, all samples from groups A and B probably also had fabric I, but this fabric has been 
gradually replaced or even transposed by fabric II due to the thermal effect of dyke intrusion. This indicates that temperature reached at least 300-400 ${ }^{\circ} \mathrm{C}$ during intrusion. However, this temperature should be considered as a maximum because of time differences between experiment and nature. In the later case, the process takes much longer and, therefore, temperature could be lower to produce effects similar to the experiments.

The effects of heating as a function of distance from dyke and of dyke thickness are well illustrated by variations in the value of parameters like $Q$. These variations highlight: 1) the absence of significant effects of heating on the SE margin of the thinner FZ11A dyke; 2) a moderate effect on the NW margin of the same dyke (facing the thicker FZ11B dyke); 3) a larger effect on the NW margin of the thicker FZ11B dyke; and 4) maximum effect on the SE margin of FZ11B (facing the thinner FZ11A dyke). This indicates a significant effect on sediments located between the FZ11 dykes (i.e. sediments heated by both dykes) than for sediments outside both dykes. On the other hand, a variation of $Q$ comparable to that obtained in the first $2 \mathrm{~m}$ away from FZ11B has been found in FZ8, along ca. $45 \mathrm{~m}$, with higher values close to the dyke margin. Such characteristics show the existence of a temperature gradient during intrusion clearly depending on the thickness of the dyke.

\section{Conclusions}

Variations of the bulk magnetic properties are sensitive to the observed mineralogical and textural transformations due to the thermally induced re-crystallization and Fe-metasomatism. In this geological framework, the newly formed hematite content in the matrix reflects the metasomatic intensity experienced by the sedimentary rocks hosting the Foum Zguid dyke.

The thermal experiments of AMS on samples collected farther from the dyke and, thus, less affected by heating, indicate that $300-400{ }^{\circ} \mathrm{C}$ is the minimum range necessary to trigger appreciable transformations of the previous magnetic fabrics. For temperatures higher than ca. $580{ }^{\circ} \mathrm{C}$, the magnetic fabric transformations are fully realized, with complete transposition of the initial fabric. Therefore, measured variations of the magnetic fabric can indicate the re-crystallization temperatures experienced by the host sedimentary rock during dyke emplacement. The distinct magnetic behaviour observed along the cross-sections indicate that samples farther from the dyke margins did not experience ther- mal alteration, which suggests that temperatures did not exceed $300{ }^{\circ} \mathrm{C}$ during dyke emplacement.

The AMS data shows a gradual variation of the magnetic fabric according to distance from the dyke margin, from sub-horizontal $K_{3}$ away from the dyke, to vertical close to the dyke. Experimental heating shows that heat alone can be responsible for this measured $90^{\circ}$ variation. Therefore, such changes in orientation should not be unequivocally interpreted as the result of a stress field.

Magnetic studies prove to be a very sensitive tool to assess the variable intensity of the Fe-metasomatism and re-crystallization processes thermally induced by dyke intrusion.

\section{Acknowledgements}

This is a contribution to the research project TEAMINT (POCTI/CTE/48137/2002). We also acknowledge Centre National de la Recherche Scientifique (CNRS - France), Gabinete de Relações Internacionais da Ciência e do Ensino Superior (GRICES - Portugal) and Fundação Calouste Gulbenkian for funding. Experimental measurements have been performed at the Laboratory of Geomagnetism and Paleomagnetism of IPGP, Saint-Maur, France. We also thank Maxime Le Goff for the assistance during experimental work, as well as the anonymous reviewer whose suggestions helped improve the earlier version of the manuscript.

\section{References}

[1] F. Hrouda, P. Müller, J. Hanak, Repeated progressive heating in susceptibility vs. temperature investigation: a new palaeo temperature indicator?, Phys. Chem. Earth 28 (2003) 653-657.

[2] A.G. Abouzakhm, D.H. Tarling, Magnetic anisotropy and susceptibility from northwestern Scotland, J. Geol. Soc. (Lond.) 131 (1975) 983-994.

[3] A. Peraneau, D.H. Tarling, Thermal enhancement of magnetic fabric in Cretaceous sandstones, J. Geol. Soc. (Lond.) 142 (1985) 1029-1034.

[4] B.B. Ellwood, W. Balsam, B. Burkart, G.J. Long, M.L. Buhl, Anomalous magnetic properties in rocks containing the mineral siderite: paleomagnetic implications, J. Geophys. Res. 91 (1986) 12779-12790.

[5] M. Jelenska, M. Kadzialko-Hofmolk, Dependence of anisotropy of magnetic susceptibility of rocks on temperature, Phys. Earth Planet. Inter. 62 (1990) 19-31.

[6] A.M. Hirt, A.U. Gehring, Thermal alteration of the magnetic mineralogy in ferruginous rocks, J. Geophys. Res. 96 (1991) 9947-9953.

[7] X.Z. Li, J. Dobson, Z. Chen, W.J. Chang, T.G. St. Pierre, Multimodal investigation of thermally induced changes in magnetic fabric and magnetic mineralogy, Geophys. J. Int. 135 (1998) 988-998. 
[8] G.J. Borradaile, F. Lagroix, Thermal enhancement of magnetic fabrics in high grade gneisses, Geophys. Res. Lett. 27 (16) (2000) 2413-2416.

[9] C. Souque, P. Robion, D. Frizon de Lamotte, Cryptic magnetic fabric of tectonic origin revealed by heating of sedimentary samples from the Corbières (France), Phys. Chem. Earth 27 (2002) 1253-1262.

[10] B. Henry, D. Jordanova, N. Jordanova, C. Souque, P. Robion, Anisotropy of magnetic susceptibility of heated rocks, Tectonophysics 366 (2003) 241-258.

[11] L.J.G. Schermerhorn, H.N.A. Priem, N.A.I.M. Boelrijk, E.H. Hebeda, R.H. Verdurmen, E.A. Th. Verschure, Age and origin of the Messejana Dolerite fault-dike system (Portugal and Spain) in the light of the opening of the North Atlantic Ocean, J. Geol. 86 (1978) 299-309.

[12] A. Sebai, G. Feraud, H. Bertrand, J. Hanes, ${ }^{40} \mathrm{Ar} /{ }^{39} \mathrm{Ar}$ dating and geochemistry of tholeiitic magmatism related to the early opening of the Central Atlantic rift, Earth Planet. Sci. Lett. 104 (1991) 455-472.

[13] G. Choubert, Sur le Géorgien de l'Anti-Atlas, C. R. Acad. Sci., Paris 216 (1943) 69-70 (série D).

[14] G. Choubert, Histoire géologique du domain de l'Anti-Atlas, Géologie du Maroc, Notes Mém. Serv. Géol. Maroc, vol. 100, 1952, pp. $75-194$.

[15] G. Choubert, Histoire géologique du Précambrian de 1'AntiAtlas: t. 1, Notes Mém. Serv. Géol. Maroc 162 (1963) (352 pp.).
[16] B. Chbani, J. Beauchamp, A. Algouti, A. Zouhair, Eocambrian sedimentary record in a distensional and intracontinental basin: the cycle "basal conglomerates - limestones unit Tikirt sandstones" of the Bou-Azzer El Graara area (Central Anti-Atlas, Morocco), C. R. Acad. Sci., Paris 329 (1999) 317-323.

[17] A. Piqué, M. Bouabdelli, J.R. Darboux, Le rift cambrien du Maroc occidental, C. R. Acad. Sci., Paris 320 (1995) 1017-1024 (série IIa).

[18] D.J. Dunlop, Ö. Özdemir, Rock Magnetism: Fundamentals and Frontiers, Cambridge University Press, 1997.

[19] W. O'Reilly, Rock and Mineral Magnetism, Blackie, 1984.

[20] D.H. Tarling, F. Hrouda, The Magnetic Anisotropy of Rocks, Chapman and Hall, 1993.

[21] G.J. Borradaile, B. Henry, Tectonic applications of magnetic susceptibility and its anisotropy, Earth-Sci. Rev. 42 (1997) 49-93.

[22] V. Jelinek, Characterization of the magnetic fabric of rocks, Tectonophysics 79 (1981) 63-67.

[23] V. Jelinek, Statistical processing of magnetic susceptibility measured in groups of specimens, Stud. Geophys. Geod. 22 (1978) $50-62$.

[24] D.K. Potter, A. Stephenson, Single-domain particles in rocks and magnetic fabric analysis, Geophys. Res. Lett. 15 (1988) $1097-1100$. 